\title{
ANALYSES OF COUPLED HYDROLOGICAL-MECHANICAL EFFECTS DURING DRILLING OF THE FEBEX TUNNEL AT GRIMSEL \\ J. Rutqvist ${ }^{1}$, A. Rejeb ${ }^{2}$, M. Tijani ${ }^{3}$, C.-F. Tsang ${ }^{1}$ \\ 1)Ernest Orlando Lawrence Berkeley National Laboratory (Berkeley Lab), USA \\ ${ }^{2}$ ) Institut de Radioprotection et de Sûreté Nucléaire, France \\ ${ }^{3}$ ) Ecole des Mines de Paris, France
}

\begin{abstract}
This paper presents analyses of coupled hydrological-mechanical (HM) processes during drilling of the FEBEX tunnel, located in fractured granite at Grimsel, Switzerland. Two and three-dimensional transient finite-element simulations were performed to investigate HM-induced fluid-pressure pulses, observed in the vicinity of the FEBEX tunnel during its excavation in 1995. The results show that fluidpressure responses observed in the rock mass during TBM drilling of the FEBEX tunnel could not be captured using current estimates of regional stress. It was also shown that the measured pressure responses can be captured in both two and three-dimensional simulations if the stress field is rotated such that contraction (compressive strain rate) and corresponding increases in mean stress occur on the side of the drift, where increased fluid pressure spikes were observed.
\end{abstract}

\section{INTRODUCTION}

When tunnels are excavated in saturated rocks, peculiar responses in the fluid pressure have been observed in surrounding rocks. One example is the excavation of the FEBEX tunnel, located in fractured hard rock at the Grimsel Test Site (GTS), in Switzerland (McKinley et al., 1996). During tunnel-boring-machine (TBM) excavation of the FEBEX tunnel, distinct increases in fluid pressure were observed in boreholes located a few meters away from the drift wall (Figure 1). The increased fluid pressure typically occurred during ten-hourlong working shifts of active tunnel boring. Fluid pressure decreased during time periods of no tunnelling activity. These pressure responses are believed created by a rapid squeezing of the porous rock under increasing mechanical load in a coupled hydrological-mechanical (HM) process.

As a part of the international DECOVALEX III project, several independent research teams have analysed coupled HM effects during TBM drilling of the FEBEX tunnel. This paper presents the analyses conducted by two different research teams: Institut de Radioprotection et de Sûreté Nucléaire (IRSN) in collaboration with Ecole des Mines de Paris (EMP), who conducted a twodimensional numerical modelling, and the Lawrence Berkeley National Laboratory (Berkeley Lab), who conducted a three-dimensional transient numerical modelling. The paper focuses on the pressure responses in borehole section $\mathrm{P} 4$, which are most distinct.

\section{TWO DIMENSIONAL MODELLING}

A two-dimensional finite-element modelling was carried out by the IRSN/EMP to analyse HM effects during excavation of a circular hole in a homogeneous, isotropic, porous elastic medium. The finite-element coupled codes VIPEF (mechanic) and HYDREF (hydraulic) was used for this HM analysis (Tijani, 1996).

\subsection{Model of the FEBEX tunneling}

In this analysis, the transient tunnelling process was simulated in a two-dimensional section across the FEBEX tunnel. A coupled HM analysis was conducted using a Biot (1941) model with Young's modulus $\mathrm{E}=24.68 \mathrm{GPa}$, Poisson's ratio $v=0.37$, Biot's coefficient $b=1$ (Terzaghi assumption), and a Biot's modulus $M$ equal to infinity (the storage phenomena is caused only by skeleton strain). The hydraulic permeability was set to $7 \times 10^{-18} \mathrm{~m}^{2}$ after model calibration against observed water inflow into the FEBEX tunnel.

The TBM excavation process was modelled by a decrease of the effective force and pore pressure on the wall of the tunnel. This decrease depends on the time and the distance to the front of the excavation. The excavation was simulated according the excavation sequence shown in Figure 1 for an initial effective stress of: $\sigma_{\mathrm{H}}=\sigma_{\mathrm{h}}=29.4 \mathrm{MPa}$ (horizontal maximum and minimum compressive), and $\sigma_{\mathrm{v}}=7.14 \mathrm{MPa}$ (vertical). 


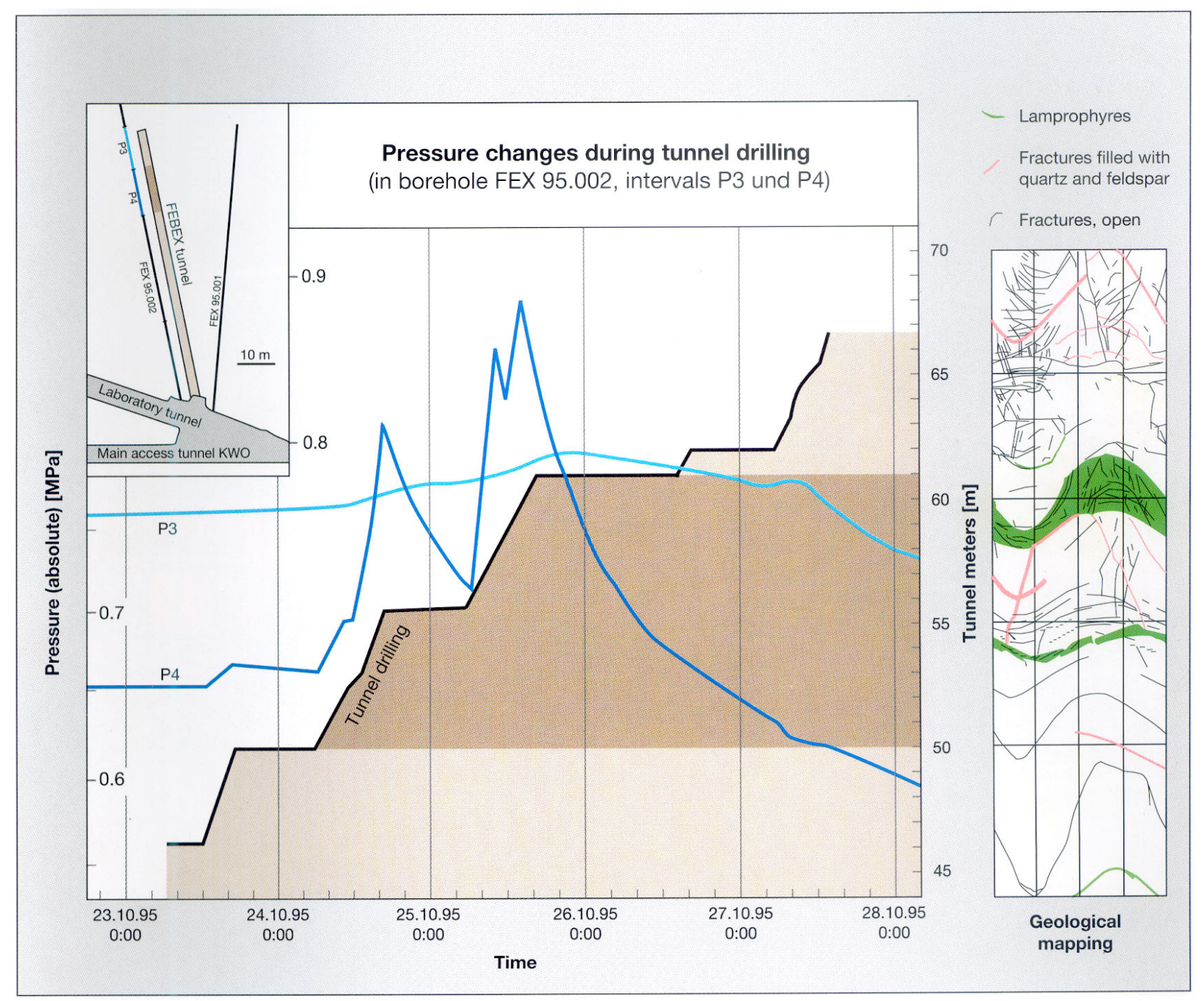

Figure 1. Pressure changes in borehole FEX 95.002 induced by the TBM drilling of the FEBEX tunnel at the Grimsel Test Site (McKinley et al., 1996).

\subsection{Strain rate}

Figure 2 shows the calculated distribution of average volumetric strain rate for the assumed stress field. The location of six points $\left(\theta=30^{\circ}\right.$ to $\theta$ $=69^{\circ}$ ) where fluid pressure changes were evaluated and interval P4 of borehole FEX 95.002 are also shown. Simulation results, as well as analytical solutions, reveal that a pore-pressure increase will only occur at the four points located in the contracted zone of compressive strain rate $\left(\theta>45^{\circ}\right.$ in Figure 2). However, the P4 interval $\left(\theta=14^{\circ}\right.$ in Figure 2) is located in the zone of extensional strain rate, and therefore no pore pressure increase can occur in at that location for the assumed stress field.

\subsection{Pore pressure variations}

Figure 3 presents the simulated pore pressure versus time at the 6 points described above and the measured pore pressure at the $\mathrm{P} 4$ interval of the FEBEX.95002. The pore pressure measured in the P4 interval $\left(\theta=14^{\circ}\right)$ agree well with the numerical results obtained from the point located at $\theta=53^{\circ}$. This means that a good agreement between measured and simulated pressure response at $\mathrm{P} 4$ could be achieved merely by changing the orientation of the initial stress. 


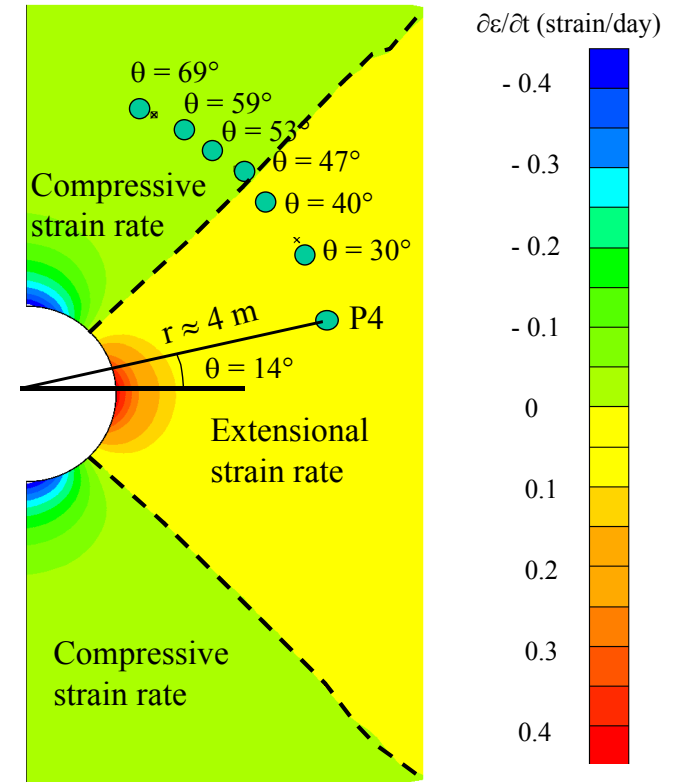

Figure 2. Simulated strain rates distribution indicating zones of contraction (compressive strain rate) and extension (extensional strain rate) and locations for evaluation of pore-pressure variations.

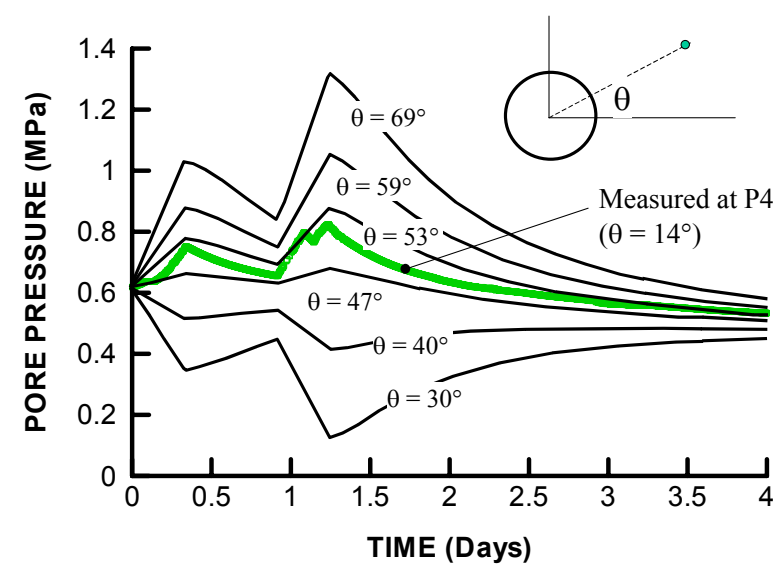

Figure 3. Simulated pore-pressure responses at points with locations shown in Figure 2, compared with measured pressure response in interval P4 of borehole FEX 95.002. Time 0 in this figure corresponds to 7:00 on October 14 in Figure 1.

\subsection{Influence of permeability and excavation duration}

The influence of rock permeability and excavation duration on the pore-pressure evolution was investigated. In this context, relative time is defined as $\tau=t / T$, where $t$ is time and $T$ is the excavation duration. Figure 4 presents the pore-pressure evolution during excavation at the point located at $\theta=53^{\circ}$ (Figure 2) with variation of permeability and excavation duration. The permeability is varied according to $k=\lambda k_{0}$, where $k_{0}=7 \times 10^{-18} \mathrm{~m}^{2}$ (reference case) and $\lambda$ takes the values $0.1,0.2$, $1,2,5,10,100$, and infinity. In addition, it can be shown that the curves in Figure 4 also represent variations in excavation duration according to $T=\lambda T_{0}$, where $T_{0}=0.35$ day. Significantly, for $k \leq 7 \times 10^{-18} \mathrm{~m}^{2}(\lambda \leq 1)$, a maximum pressure increase of $0.8 \mathrm{MPa}$ was obtained. On the other hand, for a permeability two orders of magnitude higher $\lambda=100$ ) no significant pressure increase occurred. Thus low rock permeability is necessary to simulate fluid pressure responses observed during TBM drilling of the FEBEX tunnel.

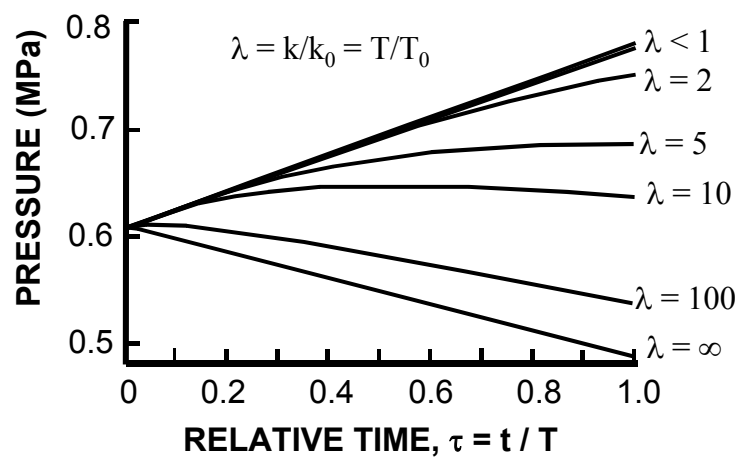

Figure 4. Simulated pore pressure evolution with variation of permeability and excavation duration. 


\section{THREE-DIMENSIONAL MODELLING}

A fully coupled three-dimensional HM modelling of the TBM drilling for the FEBEX tunnel was conducted by Berkeley Lab, using the finiteelement code ROCMAS (Rutqvist et al., 2001).

\subsection{Model conceptualization of FEBEX tunnelling}

A finite-element mesh was constructed as shown in Figure 5. The hydrological properties of the different units within the finite-element model was first estimated from local geohydrological field data and then calibrated to match observed head distribution and inflow into the open drift. An initial stress was assigned according to $\sigma_{\mathrm{v}}=10$ $\mathrm{MPa}, \sigma_{\mathrm{h}}=15 \mathrm{MPa}$, and $\sigma_{\mathrm{H}}=30 \mathrm{MPa}$, where $\sigma_{\mathrm{H}}$ is oriented $45^{\circ}$ from the axis of the FEBEX tunnel (Figure $5 b$ ). These values are within the range of stress measurements in the GTS area (Pahl et al., 1989).

The material properties are given in Table 1 . Except for permeability, the properties of the highpermeability zones (Lamprophyres) and the surrounding rock are the same. The mechanical rock-mass properties are obtained from the geological description of the GTS (Keussen et al., 1989). Significantly, the Young's modulus of the rock mass was reduced to $70 \%$ of its value for intact rock.

In the Berkeley Lab's numerical modelling, the FEBEX tunnel was excavated according to the actual TBM boring schedule. The TBM boring was conducted in ten-hour day shifts, from Monday to Friday, with no activities during night and weekends. The modelling was simplified such that one daily section - a section of the drift excavated during one day-was uniformly excavated during a ten-hour work shift. The excavation process in each drift section was simulated as follows:

1. Young's modulus of elements within the excavated tunnel section was set to zero.

2. Internal stress and fluid pressure within the tunnel were linearly reduced with time over about ten hours.

3. Final condition at the end of the work shift was zero internal stress and zero fluid pressure within the excavated tunnel.

The entire one-month TBM drilling of the FEBEX tunnel was simulated.
Table 1. Material properties of the rock mass used in modelling of TBM drilling of the FEBEX tunnel

\begin{tabular}{|l|l|}
\hline \multicolumn{1}{|c|}{ Parameter } & \multicolumn{1}{c|}{ Value } \\
\hline \hline Density, $\left[\mathrm{kg} / \mathrm{m}^{3}\right]$ & 2,700 \\
\hline Porosity & 0.01 \\
\hline Biot's constant, b & 1.0 \\
\hline Young's Modulus, $[\mathrm{GPa}]$ & 35 \\
\hline Poisson's ratio, & 0.3 \\
\hline Vertical permeability, $\left[\mathrm{m}^{2}\right]$ & $5 \times 10^{-18}$ \\
\hline Horizontal permeability, $\left[\mathrm{m}^{2}\right]$ & $5 \times 10^{-19}$ \\
\hline Lamprophyre permeability, $\left[\mathrm{m}^{2}\right]$ & $1.1 \times 10^{-17}$ \\
\hline
\end{tabular}

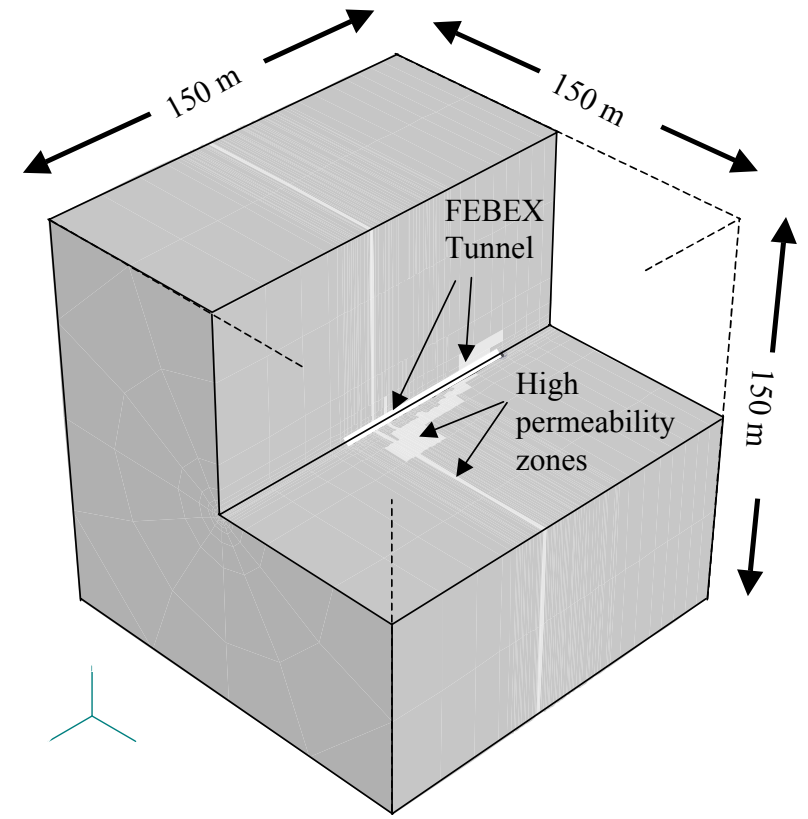

(a) Three-dimensional model geometry

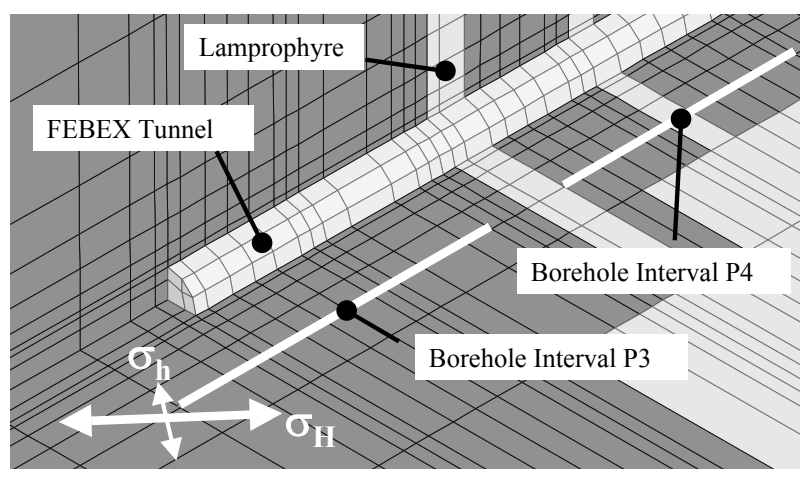

(b) Detailed view of the near field of FEBEX

Figure 5. Finite-element model for a fully coupled simulation of the one-month TBM drilling for the FEBEX tunnel. 


\subsection{Result of fluid pressure variation}

Figure 6 presents simulated changes in mean stress and fluid pressure at 18:00 on October 25, which is at the end of one-day shift, when the excavation had reached $61 \mathrm{~m}$ (Figure 1). Figure $6 \mathrm{~b}$ shows that the fluid pressure has increased in two zones: a zone around the front-left side of the excavation and a zone above the excavation, near its front. Figure 6a shows that near these two zones of pressure increase; the mean stress has increased as a result of the excavation. In contrast, the fluid pressure on the side of the drift has decreased where the mean stress has decreased. This shows that HM coupled processes induce these changes in fluid pressure.

Figure 6 also illustrates that the HM-induced changes in fluid pressure are temporal. For example, the HM-induced fluid-pressure increase above the drift is diminished 5 to $10 \mathrm{~m}$ behind the excavation front. Thus, away from the active TBM drilling, the open boundary at the tunnel wall controls the fluid pressure.

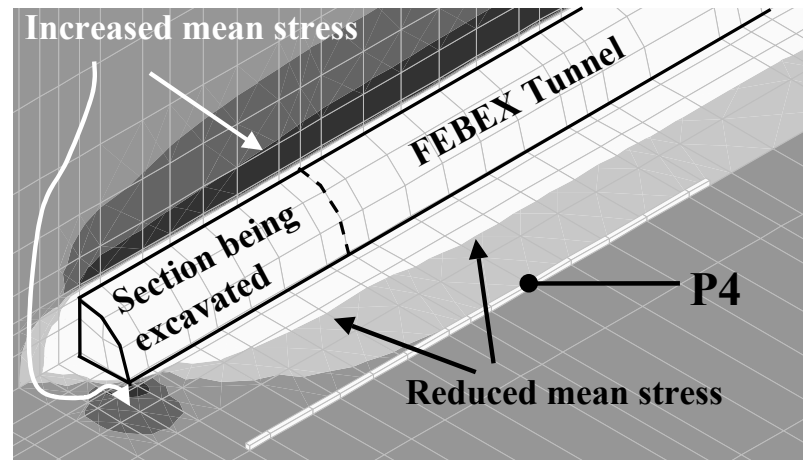

(a) Change in mean stress

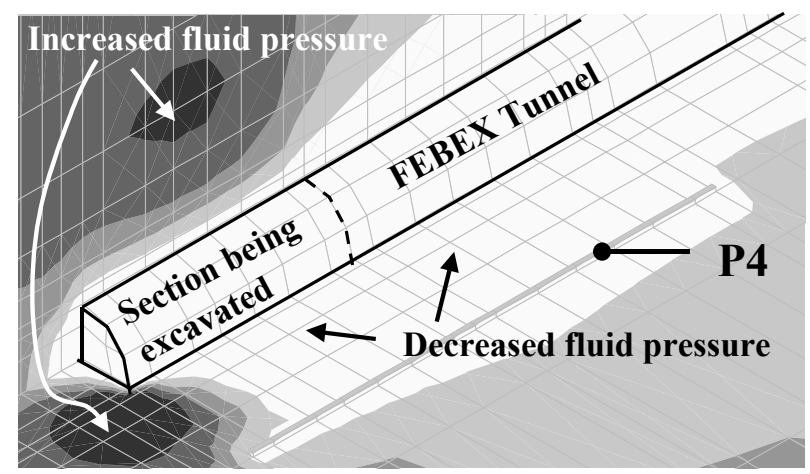

(b) Change in fluid pressure

Figure 6. Simulated changes in mean stress and fluid pressure relative to pre-excavation conditions at 18:00 on October 25 (dark contours are increases and light contours are decreases).

\subsection{Predicted pressure evolution}

Figure 7 presents predicted and measured pressure responses in interval P4. During three consecutive day shifts of active tunnel boring, both predicted and measured pressure respond when the excavation front passes parallel to $\mathrm{P} 4$ (between 7:00, October 23 to 18:00, October 25, in Figure 1). However, the predicted pressure responses are the opposite of what was measured. The measured pressure shows two peaks at 714 and 738 hours. In the simulation, on the other hand, the pressure decreases at 714 and 738 hours.

\subsection{Calibrated pressure evolution}

A parameter variation showed that the HMinduced pressure responses depend on many parameters, including rock-mass deformation modulus, Biot's coupling constants, hydraulic permeability, and the magnitude and orientation of the in situ stress field. The three material parameters affect only the magnitude of the HM-induced pressure response. On the other hand, the magnitude and direction of the in situ stress field are important factors that determine where and when the fluid pressure will increase or decrease.

An attempt was made to match the field test responses by adjusting the initial stresses in the model. It was concluded that it is possible to produce increasing pressure peaks at 714 and 738 hours in interval P4 by changing orientation and magnitude of the stress field. Basically, the vertical stress had to be substantially increased such that the TBM drilling produces a mean stress increases on the side of the tunnel. Figure 8 presents one example in which the in situ stress field has been rotated in order to match simulated and measured fluid pressure responses. 


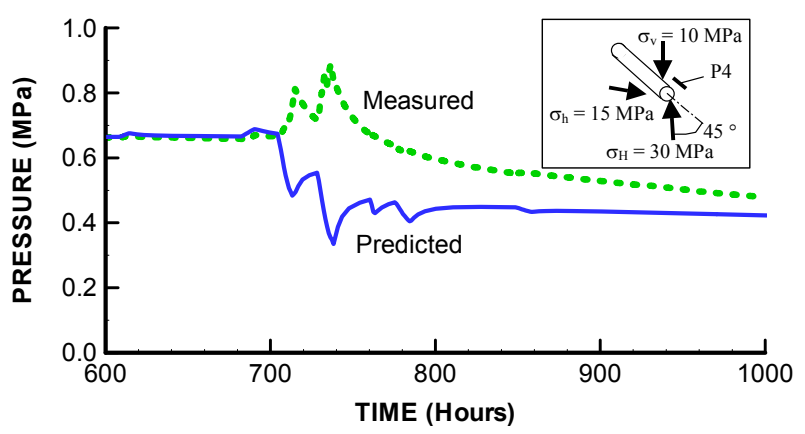

Figure 7. Predicted and measured fluid pressure evolution in interval P4 of borehole FEX 95.002, for estimated regional stress field at GTS area.

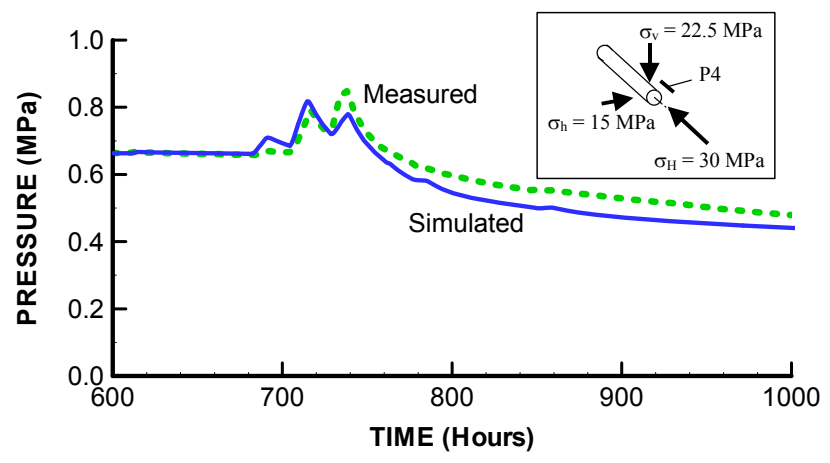

Figure 8. Simulated and measured fluid pressure evolution in interval P4 of borehole FEX 95.002, for adjusted local stress field at the FEBEX tunnel.

\section{CONCLUDING REMARKS}

The results from two and three-dimensional numerical analyses show that fluid-pressure responses observed in the rock mass during TBM drilling of the FEBEX tunnel could not be captured using current estimates of regional stress. It was shown that the measured pressure responses can be captured in both two and three-dimensional simulations if the stress field is rotated such that contraction (compressive strain rate) and corresponding increases in mean stress occur near borehole FEX 95.002 on the side of the drift. From the results of the two-dimensional analysis, it appears that good agreement between measured and simulated evolution of fluid pressure could be obtained if the maximum principal stress were rotated about $40^{\circ}\left(53^{\circ}\right.$ minus $14^{\circ}$ in Figure 2) from the horizontal. Such a rotation of the local in situ stress field is not unrealistic, especially considering the presence of the Lamprophyre zones and other geological features.

\section{ACKNOWLEDGEMENTS}

Review and comments by Dan Hawkes, Lawrence Berkeley National Laboratory are much appreciated. Financial support for the Berkeley Lab's research team was provided by a grant from the Swedish Nuclear Power Inspectorate.

\section{REFERENCES}

Biot, M. A. 1941. General theory of threedimensional consolidation. J. Applied Physics 12: 155-164.

Keusen H.R., Ganguin J., Schuler P. \& Buletti M, Grimsel. 1989. Test Site-Geology. NAGRA, NTB 87-14E.

McKinley, I., Kickmaier, W., del Olmo, C., \& Huertas F. 1996. The FEBEX project: full-scale simulation of engineered barriers for a HLW repository. NAGRA Bulletin No. 27, NAGRA, Switzerland.

Pahl, A., Heusermann, St., Bräuer, V. \& Glöggler, W. 1989. Grimsel Test Site. Rock stress investigations. NAGRA, NTB 88-39E, Apr. 1989.

Rutqvist, J., Borgesson, L., Chijimatsu, M., Kobayashi, A., Nguyen, T.S., Jing, L., Noorishad, J. \& Tsang, C.-F. 2001. Thermohydromechanics of partially saturated geological media: governing equations and formulation of four finite element models. Int. J. Rock. Mech. Min. Sci. 38(1): 105-127.

Tijani, S.M. 1996. Short description of VIPLEF code. Coupled thermo-hydro-mechanical processes of fractured media. Developments in Geotechnical Engineering, 79: 507 - 511. 